\title{
Internet Courses: Who Is Doing The Work?
}

Gary Saunders, Marshall University

Loren Wenzel, Marshall University

Charles T. Stivason, Marshall University

\begin{abstract}
The growth in Internet courses (E courses) and degrees is continuing but controls to insure academic honesty do not seem to be keeping pace with the growth in offerings. Responses to a questionnaire distributed to chairpersons of accounting departments relating to the use of controls for controlling academic dishonesty in $E$ courses indicated that respondents strongly favored requiring students to provide a digital photo ID and audio capabilities when registering for an $E$ course but rejected the idea of requiring them to provide a web cam that might be used for verifying their identity. Respondents strongly believe that students taking an E course should complete some, but not all, examinations on-line and, whenever possible, on the university web site and that they should complete some, but not all, homework assignments on-line and at the university web site whenever possible. They also tended to believe, even though they did not endorse requiring one, that students should use a web cam when completing examinations on-line and that faculty should compare the photo ID with the web cam image. However, they do not believe that students should be required to use a web cam when completing homework assignments or that faculty should compare the photo ID with the web cam image. Respondents believe that students should be required to participate in on-line chat rooms with both the instructor and with the instructor and other students. The use of a web cam and the comparison of a photo ID with a web cam image were not seen as desirable. Overall accounting chairs endorse requiring the student who enrolls in an E course to obtain some existing technology, except for a web cam, that might help control academic dishonesty. They expect the student to be prepared to spend more than $\$ 100$ to obtain the technology.
\end{abstract}

\section{INTRODUCTION}

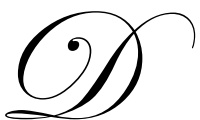

istance learning is a term used to describe a learning experience in which the instructor is in a location remote from that of the student. While distance learning is not a new instructional paradigm for universities, the delivery systems are continually evolving. For centuries distance learning has been used to educate students and, in the late 1800s, Penn State University utilized the new "Rural Free Delivery" mail system to offer correspondence courses to students in remote locations [Banas \& Emory, 1998]. Correspondence courses represented the dominant model for delivering distance learning courses for about a century. They typically required a student to finish a specific program of relatively independent study and successfully complete one, or more exams. These exams were, almost universally, proctored by an independent third party. Although correspondence courses have been offered by a number of universities, the percentage of universities offering these courses remained relatively small. Schools that have offered a degree completely by correspondence have typically not been mainstream colleges and universities but, have tended to offer paraprofessional degrees. Correspondence courses have never obtained the same degree of acceptance as traditional on-campus courses requiring a student's attendance and participation.

Developments in instructional technology provided a role for television in distance learning and, for the past few decades, universities have delivered instruction over long distances through interactive television (ITV) courses. Using a television link ITV courses allow an instructor and a student in remote locations to see one another in real-time. As a result, the connection between instructor and student is much greater than was possible with correspondence courses. Because of the technology requirements ITV courses were not available to a single student in the comfort of their home. Instead, they are usually offered only to a group of students and as an adjunct to a regularly scheduled on-campus class. This means that, unlike correspondence courses, ITV courses are not self paced but follow the same schedule of 
assignments as the on-campus companion course. Obviously, the level of control exercised by the instructor over student participation is much higher in ITV courses than in correspondence courses. While the ITV instructional model has achieved limited acceptance, its use has never been widespread enough to challenge traditional, on-campus courses as the dominant educational methodology.

During the decade of the 1990s developments in technology offered a new delivery vehicle for distance learning courses. With the rapid spread of the Internet and Email, time and space ceased to be a problem as student and instructor could engage in the learning process in real-time without the cumbersome television connections and other paraphernalia. Over the Internet a student anywhere in the world who had a computer and an Internet connection can now complete an Internet course and communicate, on a limited basis, with their instructor. New jargon was needed to describe the new environment so terms like "Internet courses," a.k.a. "E courses," Achat rooms," and "Email" were added to the academic lexicon. In the late 1990s, and until the present, E courses, "the new kid on the block," have experienced phenomenal growth and they appear to be poised to challenge traditional, on-campus courses for students. Universities seemed to sense a source of previously untapped revenue, offering courses to anyone in the world who had a computer and an Internet connection.

\section{BACKGROUND}

E courses represent an even greater departure from the traditional learning model than either correspondence or ITV courses did. In a survey of accounting chairpersons, Saunders (2002) found that by a more than 9 to 1 margin that accounting chairpersons believe that the level of control an instructor possesses with Internet courses is substantially less that with traditional courses. Uncertainty over who is actually completing the assignments in correspondence courses exists with $68.7 \%$ saying they are less certain than with traditional courses." Apparently control is an issue of concern with accounting chairpersons and, one would expect, with other administrators and faculty as well.

Many of the traditional controls available with correspondence and ITV courses are not as easily implemented with E courses. Proctoring of exams has been the norm with both of these methods but with E courses proctoring becomes much more difficult and appears to be demanded less often by administrators. When students completed a correspondence course they were typically required to obtain an objective proctor for their exams who was approved by the college or university administering the course. With ITV courses a technical person is usually required at each site to keep the equipment functioning so proctoring is typically not a problem. However, with E courses proctoring becomes much more difficult. One real advantage of Internet courses is bringing education to persons in extremely remote locations and this poses problems in locating certifiable proctors. Traditionally, proctors have been credentialed educators that were neutral with respect to the student. In population centers this type of proctor is not too difficult to locate but in the frozen tundra of Alaska or the sweltering outback of Australia, it may be impossible. In effect, when a university offers an Internet course with no required campus visits and no proctors for the exams, it gives up virtually all of the traditional controls over the course and accepts on faith that the student receiving credit for the course is the same person who completes the assignments.

Perhaps to a greater degree than for correspondence courses, Internet courses are appropriate only for students who are highly motivated and capable of working independently with a minimum of personal instruction. Smith [Smith, IAEC 2000] discussed some of the advantages and disadvantages of Internet courses and pointed out, among others, the following disadvantages.

1. Internet courses are not for all students,

2. Students must have the requisite computer skills to complete an Internet course,

3. Face-to-face interaction is missing,

4. Courses must be prepared in detail and approved before being offered and are rather unyielding to change,

5. Communications must be very precise and many students and faculties are not proficient at communicating explicitly. 
Given the challenges that Internet courses present, colleges and universities would be expected to proceed cautiously and test carefully before implementing Internet courses and degree programs. To the contrary, however, they have activated courses and programs at a surprising rate. The 1993 Peterson's College Guide listed 93 'cyberschools' and the 1997 Distance Learning Guide listed 762. That represents a phenomenal growth of more than 700 percent. Vasarhelyi and Graham [1997, p. 32] state that "in the last two years, the emergence of the Internet has opened the doors for a permanent revolution in the classroom and educational processes. . A About 55\% of America's 2,215 colleges and universities have courses available off site." By 1998 approximately 1,680 institutions were offering about 54,000 E courses with 1.6 million students enrolled. Svetcov reported that in:

December 1999, the National Center for Educational Statistics (NCES) of the U.S. Department of Education (USDE) released a national survey on what it calls Adistance learning" in higher education. In 1997-98 almost 44\% of all higher education institutions offered distance courses. Larger institutions moving faster; 87\% of those with more than 10,000 students offered distance classes while only 19\% of institutions with fewer than 3,000 students did so. Total enrollment in postsecondary, credit-granting distance learning courses in 1997-98 was 1,363,670; the number has grown considerable since, although as yet there are no firm figures. [Forbes, 2000]

The American Federation of Teachers indicated that "distance education is one of the fastest-growing developments in higher education. Seventy percent of the nation's 4,000 two- and four-year colleges offered online courses in 2000, up from 48\% in 1998" [Black Issues in Higher Education, 2001].

Other projections call for 2.2 million students to be enrolled in Internet courses by 2002 and by 2005 it is expected to be a $\$ 46$ billion business. The term "business" would seem appropriate because, in addition to traditional nonprofit universities, many for profit businesses have sprung up to take advantage of the money making potential offered by the growth in distance learning. One website [http://www.collegeathome.com/] boasts that it can show you "over 500 U.S. Universities and Colleges, ALL fully ACCREDITED, offering degrees in over 900 different fields (over 10,000 different programs offered) from Bachelor's to Doctorate's . . The website goes on to list some of the most highly respected universities in the U.S. Add to that the large number of colleges and universities that are not accredited and the more than 1,600 corporate universities [elearning, www.elearningmag.com, October, 2001] offering Internet courses and the growth in Internet course offerings is amazing.

As researchers speculate on the impact that $\mathrm{E}$ courses and degree programs will have on the traditional university, there are very important questions that are rarely asked aloud. One question is do E courses and degree programs represent a new and significant improvement over traditional pedagogy for educating students or just a lessening in the rigor of academic programs? Another is, does the lessening of the traditional controls to prevent dishonesty and insure that the person obtaining credit for a course is actually completing the exams and assignments reduce the overall validity of the course? Is it more likely that individuals will falsely obtain degrees from previously reputable colleges and universities by proxy? Eisenberg (1999) suggests that eliminating cheating on exams administered in Internet courses is not possible without a face-to-face proctor. He does concede, however, that some electronic tool are available that, while not the best cost effective approach, can help mitigate the problem of insuring that the person receiving credit for an Internet course is actually completing the requirements for the course.

Substantial research may be needed to answer those questions over a time frame of several years. In the shorter term, faculty and administrators of universities will have a major influence on whether Internet courses will be an improvement or a detriment to the educational process. They will play a vital role in crafting Internet courses and programs for their respective universities and their attitudes should provide guidance on the need for controls to maintain the integrity of the evaluation process in Internet courses.

\section{STUDY RESULTS}

Accounting department chairpersons typically play a major role in the development of Internet accounting courses and the control features incorporated in them. In order to obtain the opinions held by accounting chairpersons regarding the use of some of the available electronic tools for controlling academic dishonesty in Internet courses, a 
questionnaire was developed and $\mathrm{E}$ mailed to 471 chairpersons of accounting departments at universities and colleges in the U.S. Of that 471, 69 were undeliverable because of addressing problems leaving 402 delivered questionnaires. A total of 56 responses $(14 \%)$ were received. Statements in the questionnaire related to the demographics of the respondent's school and program, some physical controls that are currently available to insure the integrity of the evaluation process, and the application of those controls in administering E courses.

Questionnaires were sent via E mail and three different response modes were suggested. If respondents were concerned about anonymity, it was suggested that they either 1) print the questionnaire, complete it, and mail it to the author or, 2) click on an Internet address and complete a web page version. Both of these response methods would help insure anonymity. The third method of responding was to choose "reply" in their E mail program, complete the questionnaire, and click on "send." Responses began arriving within hours of the initial mailing.

\section{Physical Enhancements}

A number of statements dealt with the possibility of requiring certain controls, such as the use of digital photos for identification or using web cams and audio capabilities for communicating in chat rooms, for students completing an E course. Figure 1 indicates that only about $6 \%$ of the respondents objected to requiring students to provide a digital photo when registering for an E course while more than $66 \%$ agreed that it should be used. This photo could then be used for confirming the identity of the student who completed exams or homework assignments on-line or engaged in chat room sessions. This control measure is relatively cost free and that may be a factor in the recommendation by twothirds of the accounting chairpersons that it be used.

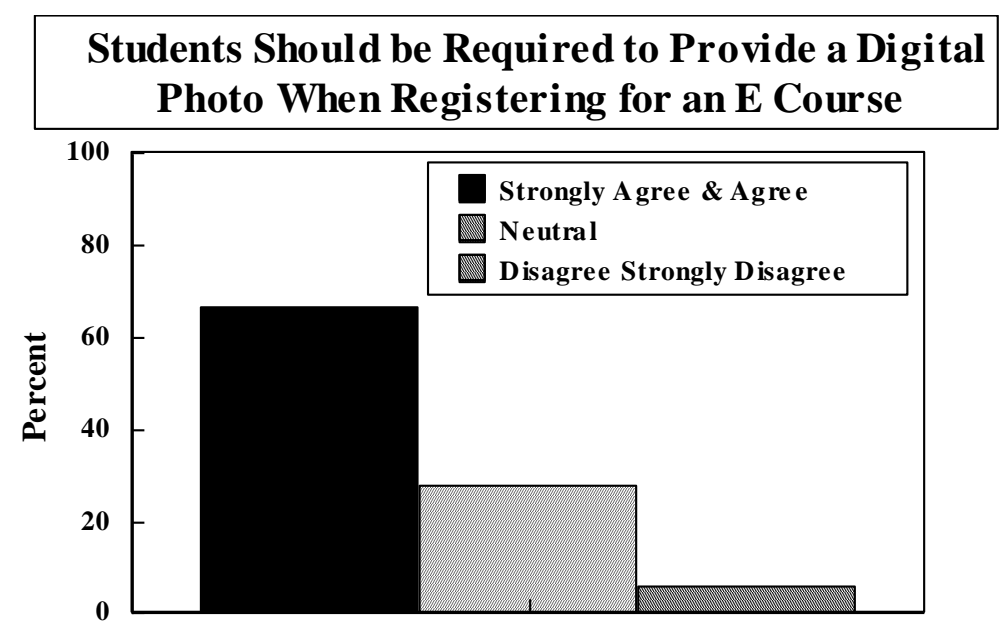

Figure 1

As shown in figure 2, a larger percentage, slightly over $35 \%$, disagreed with requiring a student to provide a web cam when registering for an E course. Still, with more than $25 \%$ agreeing and nearly $40 \%$ neutral, almost two-thirds did not object to the requirement. The perceived cost of a web cam may have influenced those who objected.

Another statement considered requiring the student to obtain audio capabilities when registering for an E course. Audio capabilities would not only act to improve control but would also make student-instructor conferences much more productive. As shown in the figure 3,53\% agreed or strongly agreed that students should be required to obtain audio capabilities when registering for an E course. With more than $37.2 \%$ of the respondents being neutral and only $9.8 \%$ disagreeing with the requirement, more than $90 \%$ did not object. 


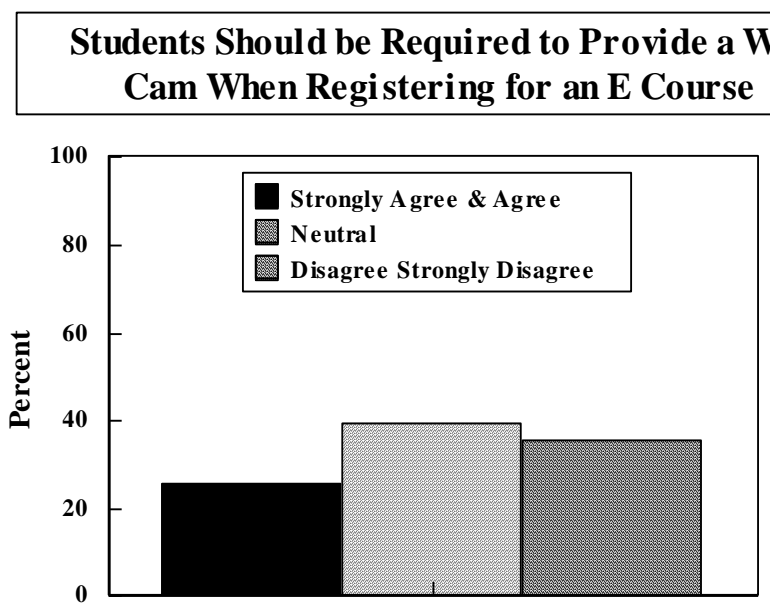

Figure 2

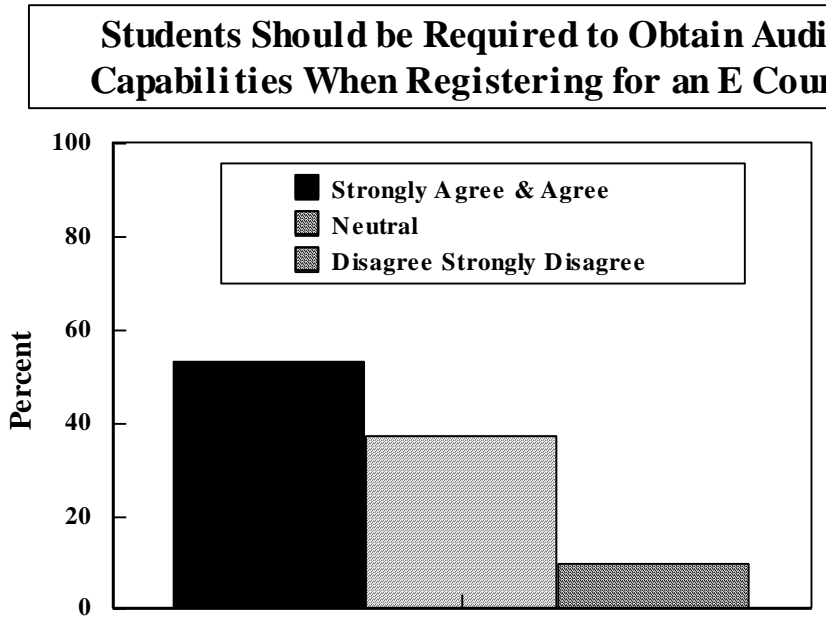

Figure 3

A related statement said "in order to obtain the 'desired technology' for completing an 'E course,' students should be prepared, if necessary, to spend the following amount of money to upgrade their computer." As the response percentages in the figure 4 indicate, almost $40 \%$ indicated that students should be prepared to spend more than $\$ 150$ to upgrade their computers for an E course and another $20 \%$ said they should be prepared to spend from $\$ 100.01$ to $\$ 150.00$ for the upgrade. Clearly, the average respondent expects the student to be prepared to invest more than $\$ 100$ to upgrade their computer for an E course. That amount would easily cover the cost of a web cam and audio capabilities and the failure of a larger percentage to recommend requiring a web cam suggests that many respondents are unaware of the low cost of these upgrades. This statement was placed after the two statements relating to obtaining a web cam and audio capabilities and, presumably, this statement did not influence responses to those two. 


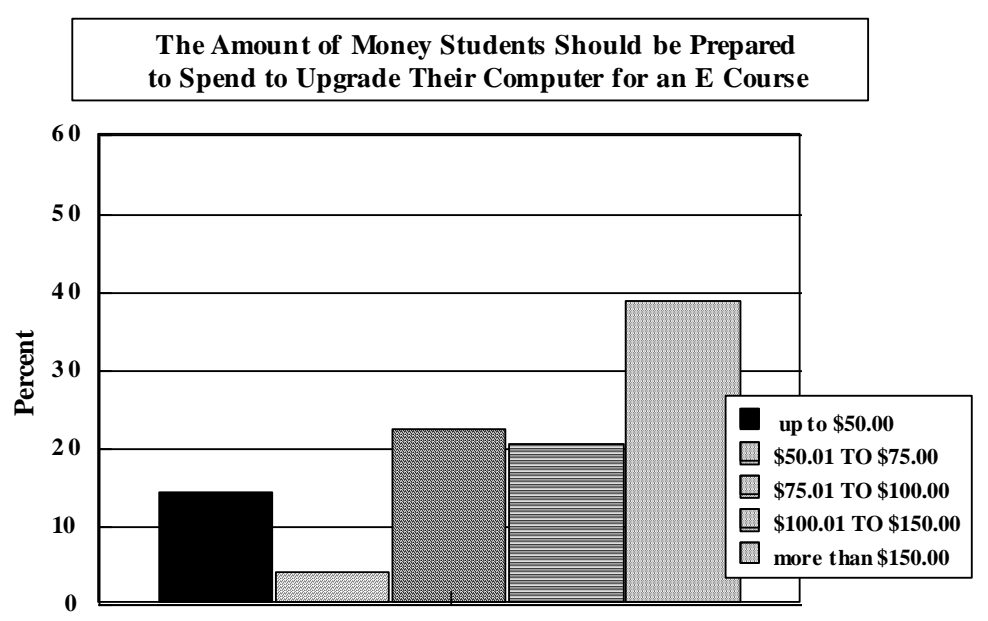

Figure 4

\section{Completing Examinations On-line}

A number of statements related to the application of controls to reduce academic dishonesty utilizing the physical enhancements discussed above and other Internet options. One statement said "students taking an "E course" should be required to complete "some examinations" on-line," and a second indicated that "students taking an "E course" should be required to complete "all examinations" on-line." As figure 5 demonstrates, only about $12 \%$ of the respondents disagreed with the requirement to complete some examinations on-line while almost $70 \%$ (68.7) agreed or strongly agreed with the control.

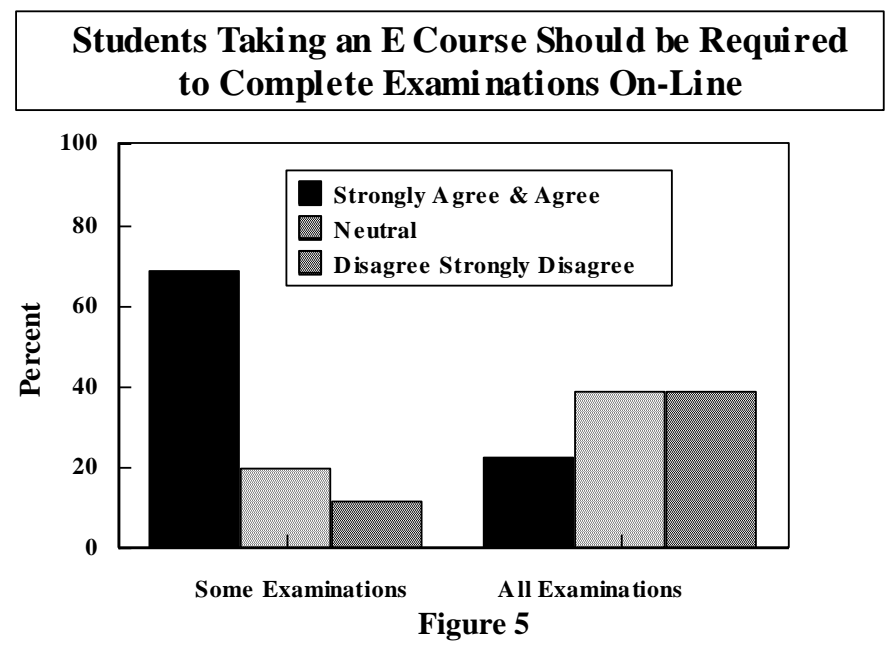

Attitudes were less supportive of requiring that all examinations be completed on-line. Only $22.4 \%$ agreed and $38.8 \%$ disagreed with the idea while the other $38.8 \%$ were neutral. Still, less than half of the respondents expressed disapproval for requiring that all examinations be completed on-line. Obviously, when students complete examinations on-line the instructor can exercise a higher degree of control over the process. 
Two statements related to the use of a web cam when students were taking examinations on-line. The first said "students taking an "E course" should be required to use the "web cam" when completing examinations on-line." As seen in figure 6, more than $40 \%$ (42.9) of the respondents either agreed or strongly agreed that students should be required to use the web cam when completing on-line examinations. A smaller percentage, 24.4, disagreed with the statement and the remaining $32.7 \%$ were neutral. The fact that $42.9 \%$ agreed with the statement is interesting because only $25.5 \%$ believed that students should be required to provide a web cam when registering for an E course. Perhaps respondents to this statement presumed that the student had a web cam available.

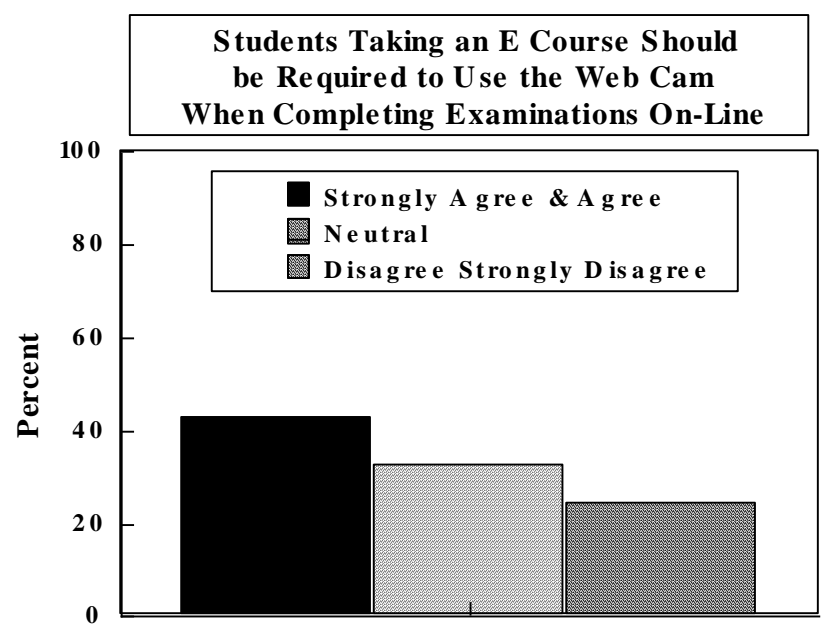

Figure 6

A related issue is the possibility that the student registered for the course is not the student actually completing the on-line examination. Another statement said Afaculty should compare images from a photo ID with the "web cam" image when monitoring examinations completed on-line to insure that the student registered is actually completing the examination." As shown in figure 7, almost half (44.9\%) of the respondents agreed with the statement while only $20.4 \%$ disagreed. With about $80 \%$ not objecting to the use of digital photo IDs as a control measure when monitoring on-line examinations, the measure appears to be an acceptable method of insuring that the student taking the exam is the same student who registered for the course.

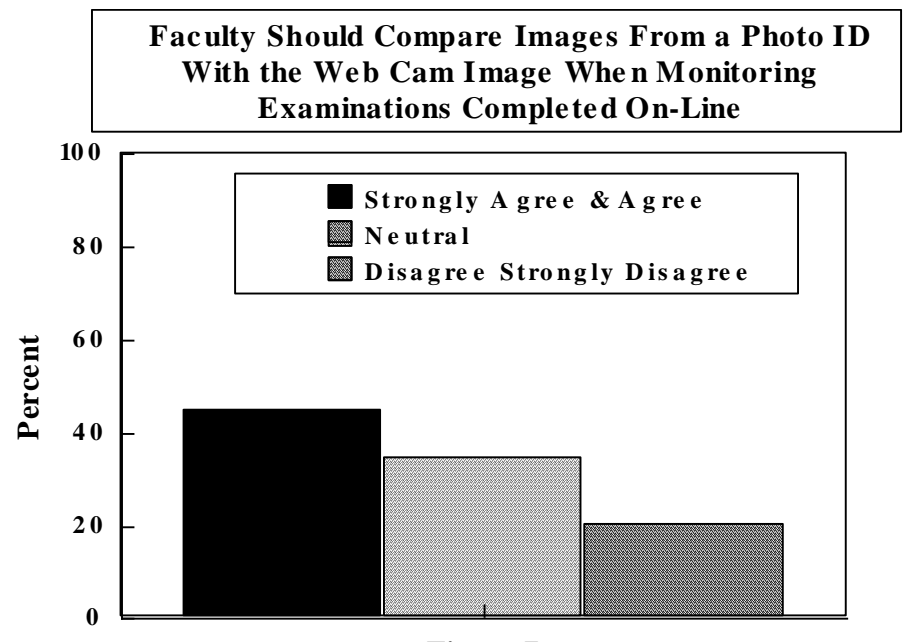

Figure 7 


\section{Completing Homework Assignments On-line}

Four statements examined attitudes about requiring students to complete homework assignments on-line. One stated that "students taking an "E course" should be required to complete some homework assignments on-line." A second said Astudents taking an "E course" should be required to complete all homework assignments on-line." Responses to the two statements, shown in figure 8, were very similar to responses to the statements indicating that students should be required to complete examinations on-line. A total of $85.7 \%$ agreed or strongly agreed with requiring students to complete some homework assignments on-line and $68.7 \%$ agreed or strongly agreed with requiring some examinations to be completed on-line. Only $6.1 \%$ disagreed with requiring students to complete some homework assignments on-line. Respondents strongly believe that students taking an E course should complete some examinations and some homework on-line.

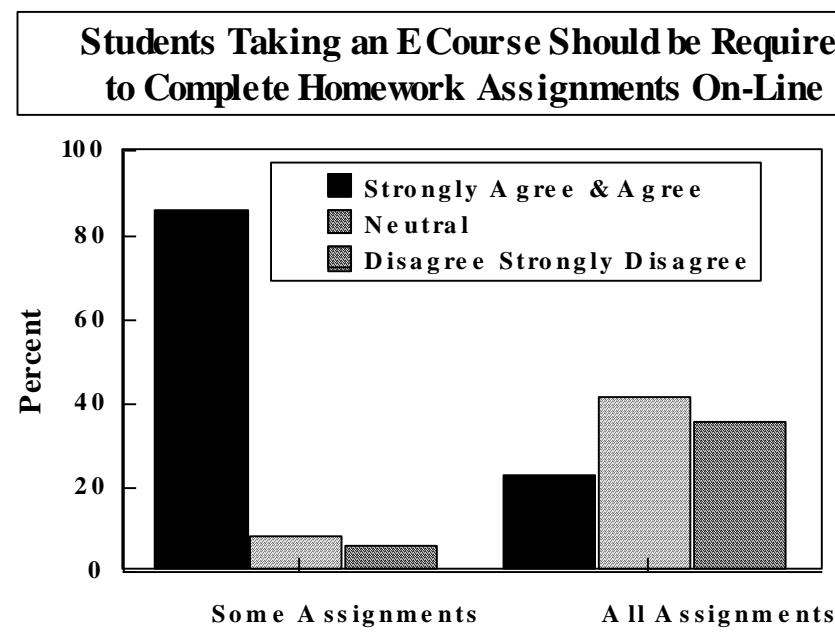

Figure 8

Respondents were much less supportive of requiring students to complete all homework on-line. Only $23 \%$ agreed while $35.4 \%$ disagreed with the statement. These percentages are very similar to the $22.4 \%$ agreeing and the $38.8 \%$ disagreeing with the statement that students should complete all examinations on-line. Apparently respondents believe that completing some examinations and homework assignments on-line is beneficial but to require completion of all examinations and homework on-line is too burdensome.

Again, the potential for a "substitute" to complete assignments on-line exists. One statement said "students taking an "E course" should be required to use the "web cam" when completing homework assignments on-line." As seen in figure 9 , only a small portion $(10.2 \%$ ) of the respondents agreed with the statement and almost six times as many (59.2\%) disagreed. That is down sharply from the $42.9 \%$ that agreed students should use a web cam when completing examinations on-line. Apparently, respondents believe that verifying the identity of students completing homework assignments on-line is not important. 


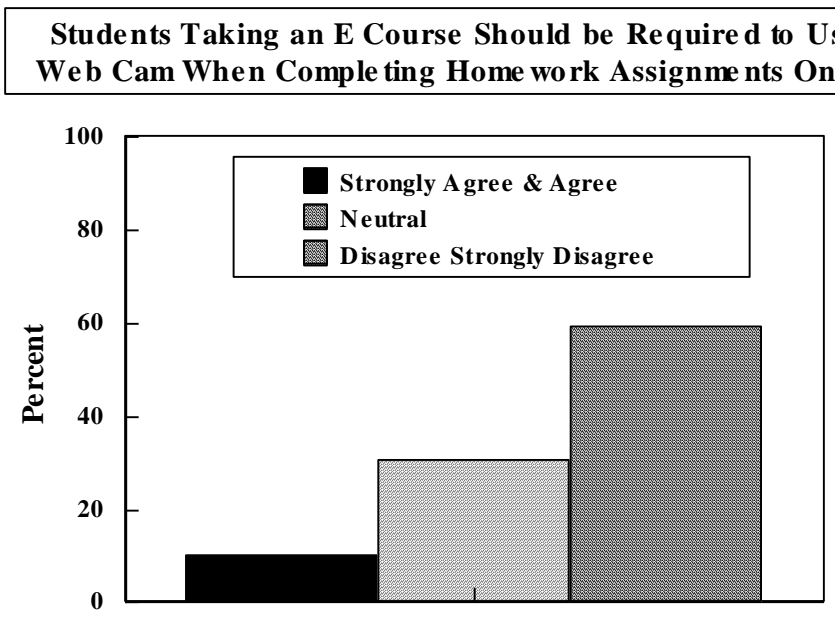

Figure 9

That point seems to be borne out by responses, in figure 10 , to the next statement which said "faculty should compare images from a photo ID with the "web cam" image when monitoring homework assignments completed on-line to insure that the student registered is actually completing the assignment." Although about $10 \%$ of those disagreeing with the previous statement moved to the agree category, still only $20.9 \%$ agreed and 50\% still disagreed. Perhaps accounting chairs do not believe that homework assignments are important enough factors in the grading process to motivate employing the use of a surrogate to complete the assignment or to use control measures to insure the identity of the person completing the assignments.

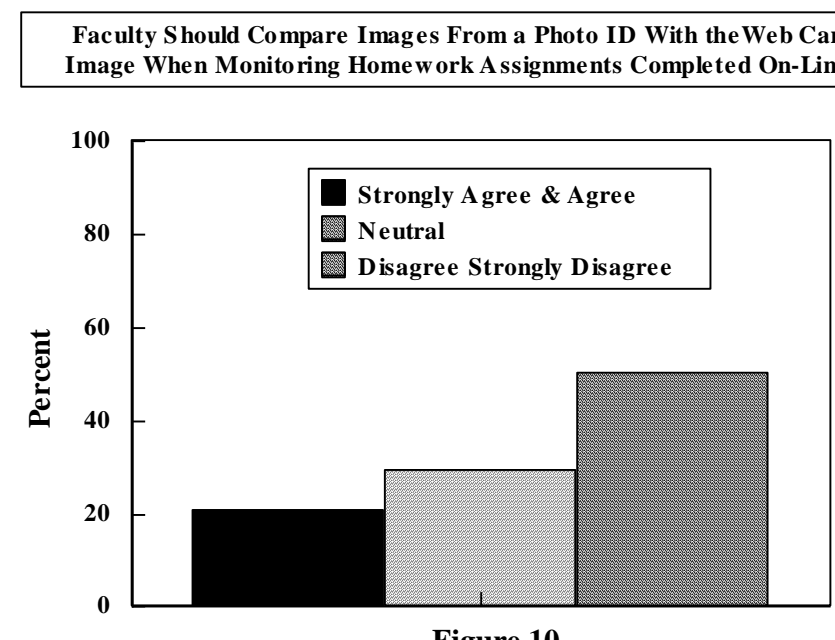

Figure 10

\section{FUTURE TRENDS}

Despite the notable failures (see "Debating the Demise of NYUonline'," 2001) the growth of Internet courses continues unabated. In fact, one university has taken the unusual step of requiring students to complete a distance learning course (Carr, 2000) as part of their traditional campus degree program. Whether the move is intended to strengthen the on-campus degree programs or to shore up a failing distance learning effort is debatable. 
Shank (2000) says that "universities want to deliver courses via the web ... because they are frightened that someone will do it before them and gain more prestige or more student revenue." He adds that "VUs (virtual universities) today seem to be for students that don't have the time to go to real schools. Students get a lot second rate education consisting of a lot of reading and watching that are interrupted, if they are lucky, by someone's comments on their homework. Sounds like correspondence school, doesn't it? That's what it really is ..."

Oblinger and Kidwell point out that "with distance learning education many of our long-held notions are turned upside down" and Hereford indicates that there is "virtually no consistency in online college courses." Bates observes that "distance learning may be well-suited to some entry level technologies, but more advanced training and hands-on labs still work best in the classroom ..."

"People who get takeout Chinese food are pretty satisfied with it, because they don't want to go out to a restaurant or cook. But generally, is the quality comparable to a restaurant? No." That quote by Bertagnoli (2001) may pretty well sum up the state of online education at this point in time. While educators, administrators, and other stakeholders may disagree about the current state and future direction of Internet education, its continued growth seems certain. Therefore, continued research is vital if the phenomenon is to develop into an effective complement to traditional on campus courses and programs. The perceived integrity of the process and quality and of the courses must be improved as part of the development.

\section{CONCLUSIONS}

The growth in Internet courses (E courses) and degrees is continuing and some sources place the number of institutions offering on-line degree in the 1,100 range and the number of degree programs at about 3,500. However, controls to insure academic honesty do not seem to be keeping pace with the growth in offerings. Some have suggested that we will have to accept a measure of academic dishonesty until technology catches up and it can be prevented. Technology is available now that can discourage and prevent much of the cheating in E courses.

Responses to a questionnaire distributed to chairpersons of accounting departments in the U.S. relating to the use of controls that are available, to varying degrees, today for controlling academic dishonesty in E courses indicated that respondents strongly favored requiring students to provide a digital photo ID and audio capabilities when registering for an E course but rejected the idea of requiring them to provide a web cam that might be used for verifying their identity. Accounting chairs indicated that a student registering for an E course should be prepared to spend more than $\$ 100$ to upgrade their computer.

Respondents strongly believe that students taking an E course should complete some, but not all, examinations on-line and, whenever possible, on the university's web site. They also tended to believe, even though they did not endorse requiring one, that students should use a web cam when completing examinations on-line and that faculty should compare the photo ID with the web cam image. Regarding homework assignments, accounting chairs believe that some, but not all, homework assignments should be completed on-line and at the university's web site whenever possible. However, they do not believe that students should be required to use a web cam when completing homework assignments or that faculty should compare the photo id with the web cam image. Respondents believe that students should be required to participate in on-line chat rooms with both the instructor and with the instructor and other students. The use of a web cam and the comparison of a photo ID with a web cam image were not seen as desirable.

Overall accounting chairs endorse requiring the student who enrolls in an E course to obtain some existing technology, except for a web cam, that might help control academic dishonesty. They expect the student to be prepared to spend more than $\$ 100$ to obtain the technology. Additionally, they believe that students should complete some examinations and homework assignments on-line and at the university's web site if possible.

Distance learning, utilizing Internet courses, may or may not represent the future for universities, but there can be little doubt that Internet courses will have an impact on the traditional university. Perhaps the conventional wisdom is to embrace the trend in the hope of surviving as a viable institution. 


\section{SELECTED REFERENCES}

1. _ New AFT Report Proposes Standards for Online Programs, Black Issues in Higher Education Vol. 17, Issue 5, February 1, 2001, p. 43.

2. Accredited College Degrees by Correspondence, http://www.collegeathome.com/, 2002.

3. Banas, Edward J. and Emory, W. Frances, History and Issues of Distance Learning, Public Administration Quarterly, p. 365-383, v. 22, issue 3.

4. $\quad$ Bertagnoli, Lisa, Education Reservation, Marketing News, Vol. 35, Issue 4, February 12, 2001.

5. Carnevale, Dan, Turning Traditional Courses Into Distance Education, Chronicle of Higher Education, Vol 46, Issue 48, August 4, 2000, p A37-9.

6. Carr, Sarah, A University Moves to Require Distance Courses, Chronicle of Higher Education, Vol. 47, Issue 8, October 20, 2000, p A48.

7. Deakin, Michelle Bates, The Failings of Distance Learning, Computerworld. Vol. 35, Issue 5, 2001.

8. elearning, http://www.elearningmag.com/, October, 2001.

9. $\quad$ Eisenberg, Daniel, Cheating in the Virtual University, Virtual University Journal, February, 1999.

10. Gaskin, James E. \& Calera, Robert E., Virtual Learning Struggling to Make the Grade, Interactive Week, Vol 7, Issue 4, August 28, 2000, p 28-9.

11. Hagen, A. \& Omolayole, O., The Impact of Technology Mediated Distance Learning on American Business Colleges: an Empirical Investigation, Proceedings of the OOICTL-Business 2000 International Conference, p. 143-6, September, 2000. Shreveport, LA.

12. Hereford, Lady, Virtually No Consistency in Online College Courses, Community College Week, Vol. 12, Issue 15, March 6, 2000, p 8-9.

13. McCartney, L., Virtual MBA -- Going Back to School Doesn't Have to Mean Sitting in a Classroom Again, Informationweek, Nov., 1996, p 32-36.

14. Noam, E. M., Electronics and the Dim Future of the University. American Society for Information Science. Bulletin of the American Society for Information Science, 22(5), 1996, p 6-11.

15. Oblinger, Diana \& Kidwell, Jill, Distance Learning Are We Being Realistic? Educause Review, Vol. 35, Issue 3, May/June 2000, p 30-37.

16. Oppermann, O., E-mail Surveys - Potentials and Pitfalls, Marketing Research, 7(3), 1995, p 29-33.

17. Roach, Ronald, The Army Marches Into Online Learning, Black Issues in Higher Education Vol. 17, Issue 24, January 18, 2001, p. 32-3.

18. Schank, Roger C., The Virtual University, CyberPsychology \& Behavior, Vol. 3, Number 1, 2000.

19. Schuldt, B. A., \& Totten, J. W., Electronic Mail Vs. Mail Survey Response Rates, Marketing Research, 6(1), 1994, p 36-41.

20. Saunders, Gary, A Comparative Analysis of Distance Learning Delivery Methodologies, presented to the 9th IAAER World Congress of Accounting Educators, Hong Kong, China, November, 2002.

21. Smith, W., The Advantages and Disadvantages of Online Delivery of Accounting Courses: Pitfalls to Avoid, Presented at the Fiftieth International Economics Conference, October, 2000. Charleston, SC.

22. Svetcov, Danielle, The Virtual Classroom vs the Real One, Forbes, Vol. 166, Issue 7, p. 50-52, September $11,2000$.

23. Vasarhelyi, M. A., \& Graham, L., Cybersmart: Education and the Internet, Management Accounting, Aug., 1997, p 32-36.

24. Vazzana, G., \& Bachmann, D., Fax Attracts, Marketing Research, 6(2), 1994, p 18-25. 
NOTES 